\title{
PERANAN KH. ABDUL WAHID HASYIM DALAM PEMERINTAHAN INDONESIA TAHUN (1945-1953)
}

\author{
Oleh: \\ Agung Syahriman dan Agus Mulyana ${ }^{1}$
}

\begin{abstract}
This research entitled "The role of KH.Abdul Wahid Hasyim In Indonesia Administration (1945-1953)". The research background addressed KH. Abdul Wahid Hasyim figure, who was the main pioneer in the Religious Ministry during the Unitary State of the Republic of Indonesia. During the Japanese occupation, the Religious Ministry called Shumubu, which was the embryo of the present Religious Ministry. As before independence took place, KH. Abdul Wahid Hasyim has been heavily involved in several movement organizations fighting against the occupation in Indonesia. Namely Nahdlatul Ulama (NU), in Majelis Islam A'la Indonesia (MIAI), and also within the Indonesian Muslim Shura Council (Masyumi) organization. In additional KH. Abdul Wahid Hasyim was involved in BPUPKI, the Sembilan Committee and PPKI who supported the emerge and the state of Indonesia. After entering the independence period, KH. Abdul Wahid Hasyim participated in several cabinets and his position once served as a State Minister, Religious Minister of the Republic of Indonesia, and as Religious Minister the Unitary State of the Republic of Indonesia.
\end{abstract}

Keywords: KH. Abdul Wahid Hasyim, Independence, Religious Minister

\section{PENDAHULUAN}

Negara Indonesia merupakan Negara yang merdeka pada tahun 1945, sama halnya seperti Negara lain, Indonesia sempat mengalami penjajahan Negara asing. Belanda dan Jepang ialah dua Negara yang sempat menduduki dan menjajah Negara Indonesia. Periode awal ialah dengan kedatangannya bangsa asing yang dimulai dengan datangnya orang-orang Belanda ke Indonesia dengan maksud dan tujuan untuk memperoleh rempah-rempah dan hasil kekayaan negara Indonesia.
Periode kedua ialah periode kedatangan orang-orang Jepang ke Indonesia. Pada tahun 1942 Jepang datang ke Indonesia dengan kepentingan Jepang bagi Indonesia untuk menyusun dan mengerahkan perekonomian Indonesia dalam rangka untuk menompang upaya perang Negara Jepang dalam kancah perang Dunia. Masa pendudukan Jepang merupakan salah satu periode yang paling menentukan bagi Indonesia. Perubahanperubahan luar biasa sempat terjadi dan memungkinkan untuk terjadinya Revolusi Indonesia.

\footnotetext{
${ }^{1}$ Agung Syahriman merupakan mahasiswa Departemen Pendidikan Sejarah FPIPS UPI. Agus Mulyana adalah dosen pembimbing. Penulis dapat dihubungi melalui alamat e-mail: Agungsyahriman@gmail.com.
} 
Peristiwa pendudukan atau penjajahan oleh bangsa asing tersebut sempat menjadikan keadaan Indonesia ada pada keadaan yang paling dasar, dengan kata lain Indonesia ada dalam keadaan terjajah. Namun keadaan tersebut bukan sematamata tidak ada perlawanan dari para pribumi. Banyak tokoh-tokoh pribumi yang terlibat dalam perlawanan tersebut, mulai dari perlawanan melawan Belanda ataupun perlawanan melawan pendudukan Jepang. Dari sekian tokoh-tokoh yang terlibat dalam perlawanan tersebut ada salah satu tokoh yang sedikit banyaknya berperan besar bagi kelangsungan perlawanan dan merebut kemerdekaan untuk Indonesia. KH. Abdul Wahid Hasyim ialah salah satu tokoh yang ikut serta berperan dalam kelangsungan perlawanan dan merebut kemerdekaan untuk Indonesia.

Pada tahun 1945, Revolusi yang menjadi alat tercapainya kemerdekaan bagi Indonesia. Bukan hanya merupakan kisah sentral dalam sejarah Indonesia, melainkan menjadi unsur yang kuat bagi Indonesia dengan usaha untuk mencari identitas Negara Indonesia sendiri. Masuk pada periode pembentukan Negara Indonesia. Pada tahun 1945 banyak hal menjadi dinamika yang mewarnai perjuangan Negara Indonesia. Pada 1 Maret 1945 dibentuklah Badan Penyelidik Usaha Persiapan Kemerdekaan (BPUPKI). Badan ini dipantau ketat oleh orang-orang Jepang dan badan ini bertugas untuk merumuskan dan memusyawarahkan guna mencapai kesepakatan bersama untuk membentuk Negara Indonesia.

Pada 7 Agustus 1945, diperoleh izin dari Jepang untuk membentuk suatu kepanitiaan yang didalamnya dibentuk oleh orang-orang Indonesia, pembentukan kepanitiaan ini disebut (PPKI) Panitia
Persiapan Kemerdekaan Indonesia. (PPKI) ini beranggotakan 21 orang terkemuka yang diantaranya Ir. Sukarno sebagai ketua, Moh. Hatta sebagai wakil ketua, KH. Abdul Wahid Hasyim, R. Otto Iskandar Dinata, Ki Bagoes Hadikoesoma sebagai wakil dari Jawa, dan lainnya sebagai wakil dari Sumatera, Sulawesi, dan Kalimantan.

Setelah kemerdekaan Indonesia yang dilaksanakan pada 17 Agustus 1945 ternyata bukan penentu kemerdekaan Indonesia seutuhnya, melainkan kedatangan rezim kolonial Belanda yang ingin kembali menguasai dan menduduki Indonesia. Agresi militerpun terjadi dan berahir pada tahun 1950 yang diakhiri oleh "Konferensi Meja Bundar" atau penyerahan kedaulatan sepenuhnya dari Belanda bagi Indonesia. Penyerahan kedaulatan ini menjadi titik awal bagi bangsa Indonesia memulai. Tatanan pemerintahan Negara Indonesia sedikit demi sedikit mulai berjalan dengan bantuan tokoh-tokoh yang terlibat dalam kemerdekaan Indonesia dan salah satunya KH. Abdul Wahid Hasyim.

KH. Abdul Wahid Hasyim pada masa setelah kemerdekaan Indonesia mengemban amanah menjadi Menteri Negara pada tahun 1945-1949. Setelah itu KH. Abdul Wahid Hasyim menjadi Menteri Agama RIS pada tahun 19491950, lalu berlanjut menjadi Menteri Agama Indonesia pada tahun 1950-1953 (Aboebakar, 2011, hlm. 683). Hal ini memberikan ketertarikan kepada peneliti untuk mengkaji tentang "peranan $\mathrm{KH}$. Abdul Wahid Hasyim dalam pemerintahan Indonesia 1945-1953”. Peneliti juga tertarik dengan topik ini mengingat masih ada yang perlu digali dan ditulis menjadi sebuah karya ilmiah tentang K.H Abdul Wahid Hasyim dan juga tentang peranannya dalam sejarah pemerintahan 
Indonesia, khususnya disaat $\mathrm{KH}$. Abdul Wahid Hasyim menjabat menjadi Menteri.

Alasan peneliti memilih angka tahun 1945 untuk awal dari kajian penulisan ini. Jelas, karena tahun tersebut awal kemerdekaan Indonesia. Lalu tatanan pemerintahan masih sangat baru dan masih rawan dengan pergolakan politik di internal Indonesia. Mengingat KH. Abdul Wahid Hasyim seorang yang tergolong memiliki andil dalam kemerdekaan Indonesia, peran, posisi, dan kebijakan apa saja yang ada pada masa KH. Abdul Wahid Hasyim menjabat ditatanan pemerintahan Indonesia. Kemudian pemilihan angka tahun 1953 ialah sebagai akhir dari kajian ini. Pada akhir tahun 1952 KH. Abdul Wahid Hasyim turun dari jabatannya sebagai Menteri Agama. Lalu pada tahun $1953 \mathrm{KH}$. Abdul Wahid Hasyim wafat pada usia 39 tahun.

Masalah utama yang dikaji dalam penelitian ini adalah "Bagaimana Peranan KH. Abdul Wahid Hasyim dalam Pemerintahan Indonesia tahun 1945-1953 ?". Masalah utama tersebut kemudian disusun ke dalam beberapa pertanyaan penelitian, yaitu (1). Bagaimana latar belakang kehidupan KH. Abdul Wahid Hasyim ? (2). Bagaimana latar belakang KH. Abdul Wahid Hasyim menjadi Menteri dalam pemerintahan Indonesia ? (3). Bagaimana kebijakan KH. Abdul Wahid Hasyim ketika menjadi Menteri dalam pemerintahan Indonesia?

Hasil penelitian ini dapat digunakan pada pembelajaran sejarah di sekolah khususnya pada tingkat Sekolah Menengah Atas kelas XI dan XII, dimana dapat menunjang materi tentang perjuangan bangsa Indonesia sejak proklamasi. Penelitian ini juga dapat memperkaya kajian tentang sejarah tokoh-tokoh Nasional di Indonesia.

\section{METODE PENELITIAN}

Metode yang digunakan dalam penelitian ini adalah metode historis atau metode sejarah yang meliputi pencarian dan pengumpulan data (heuristik), kritik, interpretasi, dan historiografi. Metode historis adalah suatu proses menguji, menjelaskan, dan menganalisis secara kritis terhadap rekaman serta peninggalan masa lampau (Gottschlak, 1986, hlm. 32). Pernyataan tersebut sama dengan pendapat Sjamsuddin (2007, hlm. 17-19) yang menyatakan bahwa metode historis merupakan suatu proses menguji dan menganalisa secara kritis dan sistematis terhadap rekaman serta peninggalan masa lampau.

Jika dilihat dari pernyataan di atas, dapat disimpulkan bahwa metode historis merupakan suatu metode yang digunakan dalam proses penelitian terhadap data dan fakta yang diperoleh pada masa lampau yang dilakukan secara kritis-analitis dan sistematis yang disajikan secara tertulis. Metode ini mempunyai beberapa tahapan yang harus dilakukan penulis dalam merekonstruksi peristiwa masa lampau. Dalam penelitian ini, penulis menggunakan metode historis yang lazim dipergunakan dalam penelitian sejarah. Metode sejarah merupakan petunjuk pelaksanaan dan petunjuk teknik tentang pencarian bahan, kritik, interpretasi dan penyajian tulisan sejarah. Ismaun (2005, hlm. 125-131) mengemukakan bahwa dalam metode sejarah meliputi:

1. Heuristik (pengumpulan sumbersumber);

2. Kritik atau analisis sumber (eksternal dan internal); 
3. Interpretasi (penafsiran);

4. Historiografi (penulisan sejarah).

Teknik penelitian yang digunakan oleh penulis dalam penelitian ini adalah teknik studi literatur atau studi kepustakaan. Teknik studi literatur ini merupakan teknik yang dipakai untuk memperoleh data yang bersifat teoritis, sehingga diperoleh fakta yang diperlukan dalam penulisan skripsi ini. Pengkajian dengan studi literatur akan membuat proses penelitian berlangsung lebih kritis dan analitis.

Setelah berbagai literatur dapat terkumpul serta cukup relevan untuk dijadikan sebagai dasar dan acuan penulisan, maka penulis mulai mempelajari, mengidentifikasi, dan mengkaji literatur tersebut untuk dapat digunakan dalam penelitian ini. Teknik studi literatur dilakukan dengan cara membaca serta menganalisis berbagai sumber tertulis, seperti buku, koran, majalah, jurnal dan sebagainya yang berkaitan dengan permasalahan yang dikaji, sehingga dapat membantu penulis dalam menemukan jawaban dari permasalahan yang dirumuskan.

\section{HASIL PENELITIAN}

KH. Abdul Wahid Hasyim adalah anak yang lahir dari keluarga terpandang pada saat itu. Ayahnya adalah Kiai Hasjim Asj'ari dan ibunya Nyai Nafiqah. Kiai Hasjim Asj'ari ialah pendiri pondok Pesantren Tebuireng, sekaligus pendiri organisasi kemasyarakatan Nahdlatul Ulama (NU). Sedangkan Nyai Nafiqah ialah putri dari KH. Ilyas, seorang pendiri Pesantren Sewulan Madiun. Dari latar belakang keluarganya, KH. Abdul Wahid Hasyim memiliki garis keturunan keluarga terpandang.
KH. Abdul Wahid Hasyim lahir pada hari Jumat 1 Juni 1914 di Desa Tebuireng, Jombang, Jawa Timur. Pada awal kelahirannya KH. Abdul Wahid Hasyim diberi nama Muhammad Asj'ari, nama tersebut berasal dari nama kakeknya. Namun karena menurut adat kepercayaan setempat nama tersebut terlalu berat (Sakral), sehinggal tidak lebih dari satu bulan nama tersebut diganti menjadi Abdul Wahid Hasyim

Karir pendidikan yang ditempuh oleh KH. Abdul Wahid Hasyim pada saat itu ilaha pendidikan Pesantren, dimana pendidikan Pesantren ialah pendidikan tradisional Indonesia yang bertujuan untuk menampung dan mendidikan masyarakat yang pada saat itu tidak bisa ikut bersekolah di sekolah umum seperti Holland Inlandsche School (HIS). Pendidikan Pesantren juga ialah salah satu lembaga pendidikan yang lebih mengarah kepada pendidikan Agama Islam.

Pada usia lima tahun KH. Abdul Wahid Hasyim sudah mulai belajar membaca Al-Qur'an dengan bimbingan langsung oleh ayahnya, lalu pada usia tujuh tahun KH. Abdul Wahid Hasyim sudah mulai belajar membaca dan mengkaji kitab-kitab umum yang biasa digunakan di Pesantren. Berlanjut pada usia 12 tahun KH. Abdul Wahid Hasyim sudah lulus dari madrasah Salafiyah Tebuireng. Pelajaran yang disukai KH. Abdul Wahid Hasyim ialah belajar ilmu bahasa. Dari kesukaannya tersebut KH. Abdul Wahid Hasyim memiliki kemampuan dalam beberapa bahasa, seperti bahasa Arab, Inggris dan Belanda.

Kemampuan berbahasa asing tersebut didapat KH. Abdul Wahid Hasyim dari kebiasaannya membaca buku-buku 
berbahasa Arab, Inggris juga berbahasa Belanda. Dasar kemampuan KH. Abdul Wahid Hasyim dalam berbahasa Arab diperolehnya dari kitab Mutammimah, yakni kitab yang membahas tentang tata cara berbahasa Arab tingkat menengah yang dulu sempat dipelajari pada waktu menjadi santri Madrasah Salafiyah. Sedangkan untuk dasar bahasa Belanda dan Inggris, KH. Abdul Wahid Hasyim belajar secara mandiri dengan panduan buku dan majalah, seperti majalah Tiga Bahasa salah satunya. Majalah tersebut mempelajari tentang ejaan bahasa-bahasa asing, diantaranya ejaan bahasa Belanda, Inggris dan bahasa asing lainnya, karena pada saat itu pelajaran-pelajaran umum atau pelajaran bahasa asing tidak diajarkan di Pesantren

Dalam hal pendidikan KH. Abdul Wahid Hasyim memang berbeda dengan kebanyakan orang pada saat itu. Orangorang pada saat itu kebanyakan sekolah di Holland Inlandsche School (HIS) atau sekolah umum pada jamannya. Perbedaan dalam hal pendidikan tersebut bukan tanpa alasan atau juga bukan karena keluarga KH. Abdul Wahid Hasyim tidak mampu untuk menyekolahkannya ke sekolah umum. Akan tetapi keputusan tersebut ialah satu keputusan yang diambil oleh ayahnya, karena menghawatirkan akan memicu kontroversi dikalangan para ulama yang pada saat itu sedang konta dengan Belanda (Penjajah). Maka dari itu ayah KH. Abdul Wahid Hasyim memilih agar tidak memasukan KH. Abdul Wahid Hasyim ke sekolah umum.

Pada usia 18 tahun KH. Abdul Wahid Hasyim berangkat ke Makkah, dalam perjalannya KH. Abdul Wahid Hasyim ditemani oleh saudara sepupunya M. Ilyas. Keberangkatannya ke Makkah bertujuan untuk menunaikan ibadah haji, sekaligus mendalami ilmu pengetahuan Agama seperti ilmu tafsir, hadis dan fiqih. Selain kedua tujuan tersebut KH. Abdul Wahid Hasyim juga memiliki tujuan lain, yaitu untuk melihat dan menganalisis bagaimana implementasi ajaran Agama Islam dalam kehidupan orang-orang Makkah. KH. Abdul Wahid Hasyim belajar di Makkah selama dua tahun kurang lebih. Pada awal kedatangannya di Makkah KH. Abdul Wahid Hasyim nampak tidak banyak kesulitan untuk beradaptasi, bakat intelektual yang dimilikinya sangatlah menolong, terutama dalam kemampuannya menguasai tiga bahasa, bahasa Arab, Inggris dan Belanda. Hal tersebut memberikannya kemudahan dalam berkomunikasi serta memberikan kemudahan dalam mempelajari berbagai buku ilmu pengetahuan disana.

Sepulangnya dari Makkah KH. Abdul Wahid Hasyim bergabung menjadi anggota pengajar Pesantren Tebuireng. Setelah kepulangannya juga, KH. Andul Wahid Hasyim banyak membawa perubahan, khususnya dalam memajukan Pesantren Tebuireng. Pada awal perubahan yang digagas KH. Abdul Wahid Hasyim ialah merombak sistem pembelajaran Pesantren Tebuireng, dari sistem klasik menjadi sistem tutorial. Usul KH. Abdul Wahid Hasyim tidak lama kemudian diterima oleh ayahnya, hingga segeralah dibuatkan satu madrasah yang diberi nama Madrasan Nizamiyah dengan jumlah santri sebanyak 29 orang. Dalam Madrasah Nizamiyah ini KH. Abdul Wahid Hasyim menggunakan dan menerapkan sistem pengajaran tutorial.

Secara garis besar Pesantren Tebuireng pada saat itu ada dalam kemajuan yang belum dialami Pesantren manapun. Hal 
tersebut hasil upaya dari KH. Abdul Wahid Hasyim yang memiliki keinginan untuk memajukan sistem pembelajarn Pesantren kearah yang lebih baik, lalu tujuannya tersebut juga untuk menarik minat para calon santri agar mau belajar di Pesantren. Pembaruan yang digagas KH. Abdul Wahid Hasyim ini membuktikan bahwa pendidikan Pesantren tidak kalah dengan pendidikan sekolah umum pada saat itu.

Karir organisasi KH. Abdul Wahid Hasyim dimulai dari pondok Pesantren Tebuireng. Pada tahun 1936 KH. Abdul Wahid Hasyim mendirikan organisasi Ikatan Pelajar-Pelajar Islam (IKPI) yang langsung dipimpin oleh KH. Abdul Wahid Hasyim sendiri. Tujuan awal didirikannya IKPI ialah untuk mewadahi para santri agar bisa berorganisasi, serta bertujuan untuk menampung para santri agar bisa belajar dan mendalami akademik diluar kelas. Organisasi IKPI ini ialah organisasi berbasis akademik yang didalamnya selalu mengadakan kajian-kajian terkait dengan akademik, seperti kajian sosial, politik bahkan kajian Agama. IKPI juga mempunyai sekretariat yang menyediakan beberapa pasilitas, seperti ruangan baca dan perpustakaan umum.

Pada tahun 1938 KH. Abdul Wahid Hasyim mulai masuk organisasi kemasyarakatan Nahdlatul Ulama (NU). Keputusannya masuk NU diambil atas dasar pertimbangan yang matang, serta bukan semata-mata karena NU adalah organisasi yang didirikan oleh ayahnya. Pandangan KH. Abdul Wahid Hasyim terhadap NU pada saat itu, NU memiliki nilai lebih dibanding dengan organisasi atau perkumpulan manapun. Nilai lebih terhadap NU menurut $\mathrm{KH}$. Abdul Wahid Hasyim ialah melihat organisasi
NU mampu menyebar dengan cepat ke berbagai daerah. Organisasi NU pada saat itu sudah menjangkau sedikitnya 60 persen wilayah yang ada di Indonesia, dengan waktu kurang lebih hanya sepuluh tahun. Sedangkan organisasi atau perhimpunan lain terbilang lamban dan hanya bisa menjangkau sekitar 20 persen daerah yang ada di Indonesia dalam waktu yang sama. Maka dari itu pandangan KH. Abdul Wahid Hasyim terhadap NU memiliki nilai yang istimewa.

Pada awal masuk NU, KH. Abdul Wahid Hasyim menjadi anggota pengurus ranting Desa Cukir, bidang yang ditempatinya ialah bidang Tanfidhiyah atau bidang politik dan pemerintahan. Kemudian satu tahun selanjutnya KH. Abdul Wahid Hasyim ditunjuk untuk menjadi anggota pengurus cabang NU di Jombang, dengan posisi sebagai sekretaris. Pada tahun berikutnya KH. Abdul Wahid Hasyim mulai dipilih dan direkomendasikan sebagai anggota pengurus besar NU di Kota Surabaya, dengan posisi sebagai ketua bidang Ma'arif atau bidang pendidikan dan pengajaran. Karirnya di NU secara berjenjang $\mathrm{KH}$. Abdul Wahid Hasyim tempuh mengikuti mekanisme yang ada.

Dalam kesempatannya di NU, KH. Abdul Wahid Hasyim tidak menyianyiakan posisi tersebut, terutama ketika KH. Abdul Wahid Hasyim menjabat sebgai ketua bidang pendidikan dan pengajaran. Dalam bidang pendidikan dan pengajaran ini KH. Abdul Wahid Hasyim banyak melakukan perubahan, terutama dalam hal memajukan bidang pendidikan Pesantren. Langkah awal yang dilakukan KH. Abdul Wahid Hasyim pada saat itu ialah dengan melakukan reorganisasi interal di dalam bidang pendidikan dan pengajaran NU. 
Setelah reorganisasi internal tersebut dilaksanakan, KH. Abdul Wahid Hasyim segeralah merancang beberapa kebijakan yang diantaranya menambah jumlah madrasah NU di seluruh Indonesia, menambah bobot pelajaran bagi para santri dan memperbaiki kualitas pengajarnya.

Pada tahun 1939 KH. Abdul Wahid Hasyim masuk ke Majelis Islam'ala Indonseia (MIAI). Organisasi MIAI ini merupakan organisasi yang dibentuk sebelumnya pada 25 September 1937, dengan tujuan untuk wadah peleburan dari berbagai organisasi-organisasi Islam yang ada di Indonesia, untuk mempersatukan suara-suara membela Islam, juga sebagai forum serta wadah diskusi antar golongan Islam dan sebagai sarana untuk menghadapi tekanan-tekanan dari penjajah. Dengan begitu Masuknya KH. Abdul Wahid Hasyim ke MIAI ialah sebagai wakil dari organisasi NU di dalam MIAI. Dalam konfrensi MIAI pada tanggal 14-15 September 1940, KH. Abdul Wahid Hasyim menjadi ketua Dewan MIAI yang melaksanakan Konfrensi untuk mengubah Anggaran Dasar sekaligus mengubah seluruh anggota kepengurusan MIAI dengan tujuan untuk memperbaiki jalannya organisasi MIAI.

Keberadaan KH. Abdul Wahid Hasyim dalam MIAI ternyata tidak bertahan lama. Pada tahun 1941 KH. Abdul Wahid Hasyim mundur dari jabatannya sebagai ketua MIAI. Hal tersebut dikarenakan kesibukan KH. Abdul Wahid Hasyim yang akan menggantikan ayahnya sebagai pemimpin pondok Pesantren Tebuireng. Selain alasan itu juga KH. Abdul Wahid Hasyim sibuk menjabat sebagai ketua bidang Ma'arif di NU yang sudah lama tidak terurus olehnya. Keputusan mundurnya KH. Abdul Wahid
Hasyim dari MIAI dibahas dalam rapat NU pusat, yang dilaksanakan pada September 1941.

Kabar tentang pengunduran diri KH. Abdul Wahid Hasyim tersebut diterbitkan juga dalam surat kabar Bataviaasch nieuwsblad pada tahun 1941. Dalam surat kabar tersebut disebutkan seperti berikut:

\section{Berita Indisch NAHDLATOEL OELAMA:}

Mereka menulis Sudah 4 bulan yang lalu Pemimpin Nahdlatoel Oelama, K.H. Hasjim Asjari sakit dan sudah tua, lalu siapa yang juga bertanggung jawab atas perawatan sekitar 1500 murid pesantren Teboeireng, segera ke manajemen pusat Nahdlatoel Oelama niatnya pesantren pendidikan Agama ini untuk masuk, karena dia sudah terlalu tua untuk mengurus pesantren dan juga menjadi terlalu lemah, dengan begitu menulis surat dengan pena untuk anaknya dengan beberapa permintaan, A. Wachid Hashim dan tugas A. Wachid Hashim untuk tidak membuat berat, yang sudah menjadi tugasnya dipenuhi oleh ketua departemen Nahdlatoel Oelama dan dari Ketua Umum Indonesia Dewan Islam (Madjells Islam a'la Indonesia atau M.I.A.I.). Itu tidak mungkin pekerjaannya dari tiga kantor terutama dimana untuk M.IA.I telah menjadi semakin berat, oleh karena itu Tengah K. M. Hasjim Asjari secara resmi dengan permintaannya Malam pertemuan ini dikumpulkan prmintaan kali ini sudah matang. Kami memutuskan untuk melakukan hal berikut. : Permintaan H. K. Hasjim Asj'ari, pimpinan pesantren untuk mengirim anaknya sebagai pengganti. Disamping itu, yang lainnya berat untuk mengambil 
tugas permintaan dari pimpinan dewan M.IA.I akan dibebaskan. dikabulkan. Dengan pengunduran diri ini dan harap dicatat bahwa Nahdlatoel Oelama tidak ada kesesuaian yang sama.selanjutnya untuk wakil Nahdlatoel Oelama ke M.I.A pengganti $A$. Wachid Hasyim diangkat sebagai K.H. Dachlan, konsul H.B. dari Nahdlatel Oelama (Bataviaasch nieuwsblad, nomor 16, 21 September 1941).

Berdasarkan penjelasan diatas, bisa ditarik kesimpulan dengan keluarnya keputusan tersebut, KH. Abdul Wahid Hasyim mundur dari MIAI sekaligus merubah posisi NU dalam MIAI menjadi anggota biasa saja. Dengan begitu posisi NU dalam MIAI tidak seperti sebelumnya yang selalu menduduki pucuk pimpinan dalam organisasi MIAI.

Memasuki tahun 1943 KH. Abdul Wahid Hasyim bergabung dengan organisasi Majelis Syura Muslimin Indonesia (Masyumi), didalam Masyumi KH. Abdul Wahid Hasyim menjabat sebagai wakil ketua muda. Organisasi Masyumi ialah organisasi bentukan Jepang yang didirikan bersifat inklusif sebagai organisasi yang bisa mewadahi semua organisasi Islam, lalu selain itu juga Masyumi didirikan ialah sebagai bentuk organisasi pengganti dari organisasi MIAI yang sebelumnya dibubarkan oleh Jepang karena dianggap berbahaya dan tidak bisa diawasi secara langsung oleh Jepang. Adapun tujuan utama dari pembentukan Masyumi ini ialah untuk alat penarik simpati masyarakat agar percaya kepada Jepang dengan menggunakan para tokoh pemuka Islam yang terhimpun dalam Masyumi.
Melihat keadaan Masyumi seperti itu, maka KH. Abdul Wahid Hasyim tidak tinggal diam. Segeralah KH. Abdul Wahid Hasyim berinisiatif untuk membuat suatu rencana melawan Jepang, usaha yang dilakukan KH. Abdul Wahid Hasyim untuk melawan Jepang ialah dengan cara halus, karena menurut pandangannya jika melawan Jepang secara langsung maka hanya akan menimbulkan kekacauan yang tidak ada artinya saja. Dengan begitu KH. Abdul Wahid Hasyim memilih dengan cara yang halus, yaitu dengan cara mengumpulkan dan merekrut para tokohtokoh muda dari beberapa organisasi Islam yang ada pada saat itu, seperti Mohammad Natsir, Prawoto, Harsono dan Zainul Arifin untuk memperkuat Masyumi. Para tokoh tersebut membuat suatu rencana yang bertujuan untuk memanfaatkan balik Jepang dengan cara meletakan politik santun terhadap Jepang, bermanismanis dihadapan Jepang tetapi memiliki rencana melawan di belakang Jepang. Politik santun ini digagas langsung oleh KH. Abdul Wahid Hasyim dan diikuti oleh tokoh lainnya, dengan begitu sedikitnya Masyumi bisa diselamatkan.

Pada tahun 1944 Jepang mendirikan kantor urusan Agama (Shumubu) dan (Shumuka). Kantor urusan Agama ini dibentuk dengan tujuan untuk memperkuat kedudukan Jepang di Indonesia dengan cara menggunakan para ulama yang terhimpun dalam Shumubu dan Shumuka. Pada awal didirikannya, kantor urusan Agama ini dipegang langsung oleh orang Jepang. Akan tetapi melihat respon para orang Islam yang tidak antusias terhadap kantor urusan Agama tersebut, maka pada bulan Agustus 1944 kantor urusan Agama ini dipegang dan diketuai oleh Kiai Hasjim 
Asj'ari dengan dibantu oleh KH. Abdul Wahid Hasyim sebagai ketua hariannya

Kantor urusan Agama Shumubu dan Shumuka dibentuk sebagai departemen khusus untuk menangani urusan Islam. Pada saat itu kantor urusan Agama ini ialah salah satu prioritas utama dalam kebijakan Jepang guna menciptakan masyarakat $j$ Indonesia yang teratur, terutama dalam kepentingan Jepang. Untuk mendukung efektivitas administrasi mengenai urusan Agama, maka kantor-kantor urusan Agama didirikan disetiap keresidenan. Kantor urusan Agama ini ialah cikal bakal adanya departemen Agama pada saat setelah kemerdekaan.

Pada akhir tahun 1944 Jepang sudah mulai berada dalam keadaan terjepit yang disebabkan oleh gagalnya perang Asia Timur Raya, mulai pada saat itu Jepang mengoptimalkan kekuasaannya di Indonesia. Bersamaan dengan hal tersebut di dalam kantor urusan Agama di intruksikan juga agar mengarahkan para santri dan masyarakat untuk ikut bergabung dengan tentara pembantu bentukan Jepang (Heiho). Akan tetapi intruksi tersebut ditolak oleh KH. Abdul Wahid Hasyim dan menyarankan agar para santri dilatih kemiliteran saja untuk pertahanan Jepang di dalam Negeri. Dengan posisi Jepang yang sedang terjepit pada saat itu Jepang tidak banyak berpikir, hingga pada akhirnya usulan KH. Abdul Wahid Hasyim diterima. Pada tanggal 14 Oktober 1944 dengan seijin Jepang Laskar Hizbullah dibentuk dan diresmikan (Isno, 2015, hlm. 32-34).

Laskar Hizbullah bermarkas pusat di Jakarta, setelah terbentuknya Laskar Hizbullah semua ulama dan para tokoh Islam langsung mengkampanyekan kepada seluruh umat Islam di Jawa, Sumatra, Kalimantan, Sulawesi, dan daerah-daerah lainnya untuk segera bergabung dengan Hizbullah. Pada tahun pertama Laskar Hizbullah sudah memiliki 500 anggota yang siap mengikuti pelatihan di Cibarusa, Bogor. Setelah beberapa bulan kemudian jumlah pasukan yang siap berlatih bertambah hingga 1500 orang (Redaksi Tempo, 2011, hlm. 96-97).

Gerakan baru dari kalangan Pesantren ini nampaknya tidak hanya sebatas coba-coba saja. Hal ini terlihat dari adanya tindak lanjut mengenai rencana pendidikan dan pelatihan bagi anggota Hizbullah kedepannya. Setiap Pesantren diminta mengirimkan perwakilan santrinya untuk menjalani pendidikan dan pelatihan yang diselenggarakan di Cibarusa, Bogor (Suryanegara, 2010, hlm. 102-103). Terlepas dari motif Jepang yang awalnya untuk memperkuat barisan militernya dengan membentuk barisan militer pribumi, lebih jelasnya momentum pelatihan ini sangat dimanfaatkan oleh kaum ulama. Apalagi melihat pelatihannya yang memang mengandalkan para ahli militer Jepang yang terlatih. Maka dari itu para santri memiliki bekal kemiliteran yang cukup baik dan nantinya digunakan untuk bekal ikut serta membela negara.

LatarbelakangKH.AbdulWahidHasyim menjadi menteri dalam pemerintahan Indonesia tidak terlepas dari perannya saat terlibat dalam kemerdekaan, dalam pembentukan pemerintahan begitupun setelah terbentuknya pemerintahan. Tahun 1945 adalah awal dari proses kemerdekaan Negara Indonesia, dimulai dari persetujuan diplomasi anatara pihak pendudukan Jepang dengan para tokoh pejuang kemerdekaan Indonesia. Pada 
tahun-tahun ini lah awal pembentukan Badan Penyelidik Usaha Persiapan Kemerdekaan Indonesia (BPUPKI) dibentuk. Dengan penuh rasa percaya diri, para tokoh pejuang kemerdekaan Indonesia berusaha serta bertekad dengan bersungguh-sungguh untuk mencapai kemerdekaan Negara Indonesia.

Pada bulan Maret 1945, pihak Jepang mengumumkan pembentukan Badan Penyelidik Usaha Persiapan Kemerdekaan Indonesia (BPUPKI) di Jakarta. BPUPKI ini ialah hasil dari diplomasi para tokohtokoh Indonesia dengan pemerintah Jepang yang pada saat itu sedang menduduki Indonesia. Pihak Jepang pada saat itu menyadari bahwa kemerdekaan Indonesia harus segera direncanakan dan diberikan, melihat kondisi pemerintahan Jepang pada saat itu sedang ada dalam kegagalan perang Asia.

Pada saat itu BPUPKI diresmikan pada tanggal 1 Maret 1945, dengan tujuan untuk merumuskan dan meneliti setiap hal yang menyangkut kemerdekaan Indonesia, akan tetapi dengan pengawasan Jepang didalamnya. Dalam BPUPKI terkumpul beberapa anggota yang meliputi perwakilan-perwakilan dari semua kelompok sosial, etnis, wilayah dan beberapa orang Jepang didalamnya selaku pengawas pada saat berjalannya persidangan (Kahin, 2013, hlm. 172-173).

Pada saat itu BPUPKI diketuai oleh Radjiman dan I. Yoshi (orang Jepang) sebagai wakilnya, lalu sekretaris BPUPKI pada saat itu ialah Abdul Gafar Pringgodigdo. Sedangkan anggota BPUPKI yang berjumlah 59 orang diantaranya dari kalangan Nasionalis Ir. Soekarno, Mohammad Hatta, Mansyur, Dewantara, Mohammad Yamin. Dari kalangan Islam
KH. Abdul Wahid Hasyim, Abikosnoe Tjokrosujoso, Haji Agoes Salim, KH. Ahmad Sanoesi, Ki Bagus Hadikusumo, Abdoel Kahar Moezakir, Dr. Soekiman dan KH. Abdoel Halim beserta yang lainnya. Dari kalangan Kristen atau non Islam ada beberapa orang yang terlibat, seperti Mr. A. A. Maramis, Latoeharhary dan lainnya (Lesus, 2017, hlm. 19).

Satu bulan selanjutnya setelah terkumpul para tokoh-tokoh tersebut segeralah diresmikan keanggotaannya dan segera melakukan persidangan. Pada tanggal 28 Mei-1 Juni 1945 persidangan BPUPKI yang pertama dibuka dengan bahasan pokok membahas mengenai dasar Negara. Pada saat itu banyak anggotaanggota BPUPKI yang mengajukan usulan serta pandangannya terkait dengan dasar Negara, diantaranya yang mengajukan usul serta pandangnnya yaitu Ir. Soekarno, Mohammad Hatta, Mohammad Yamin, Ki Bagus Hadikusumo, dan banyak lagi yang lainnya. Dalam persidangan ini banyak sekali anggota-anggota BPUPKI mengeluarkan pendapatnya, bahkan sampai terjadi perdebatan yang cukup panjang. Melihat situasi yang semakin kurang kondusif, ketua persidangan pada saat itu mengusulkan agar sidang ditunda sementara waktu sekaligus mengusulkan agar dibentuknya tim kecil berjumlah sembilan orang.

Pada tanggal 10-16 Juli 1945 persidangan BPUPKI kembali dilanjutkan setelah beberapa waktu sempat tertunda. Dalam rapat BPUPKI yang ke dua ini membahas tentang pelaporkan hasil kerja dari tim sembilan yang sebelumnya dibentuk. Hasil kerja tim sembilan pada saat itu dilaporkan oleh Ir. Soekarno sebagai ketua paniti, dalam pelaporan 
hasil kerja tim sembilan yang pertama menghasilkan beberapa catatan usulan dari seluruh anggota BPUPKI yang berhasil dikelompokan oleh tim sembilan menjadi sembilan jenis permasalahan. Setelah itu pelaporan yang ke dua ialah tentang rumusan undang-undang dasar beserta pembukaannya. Dalam pemaparan laporan ke dua tersebut tidak ada yang berargumen dalam artian semua peserta sidang menerima.

Pada persidangan BPUPKI yang dilaksanakan pada 13 Juli 1945 yang membahas tentang hal-hal pokok rancangan undang-undang, KH. Abdul Wahid Hasyim mulai berargumen dan mengusulkan beberapa poin penting yang diantaranya ketentuan Presiden dan Wakil Presiden harus orang Indonesia dan beraga Islam, ketentuan Agama Negara ialah Agama Islam, serta mengusulkan tujuh kata: dengan kewajiban melaksanakan syariat Islam bagi pemeluk-pemeluknya. Dengan adanya usulan-usulan yang dikemukakan oleh KH. Abdul Wahid Hasyim menjadikan rapat BPUPKI semakin memanas dan membuat perdebatan yang cukup panjang.

Dalam usulan-usulan KH. Abdul Wahid Hasyim menggambarkan rasa keIslaman yang kuat pada diri KH. Abdul Wahid Hasyim, terlebih jika melihat latar belakang KH. Abdul Wahid Hasyim yang memang besar dan didik dengan dasar keIslaman yang kuat oleh keluarganya. Dalam hal ini KH. Abdul Wahid Hasyim juga terlihat mempunyai penafsiran berbeda dengan orang lain terhadap pokok-pokok penting bagi kelangsungan kemerdekaan Indonesia.

Pendapat yang dikemukakan oleh KH. Abdul Wahid Hasyim menjadi perdebatan panjang hingga menghabiskan waktu kurang lebih dua hari. Pada saat itu yang menanggapi usulan KH. Abdul Wahid Hasyim diantaranya ialah $\mathrm{Ki}$ Bagus Hadikusumo dan KH. Ahmad Sanusi, mereka ada diposisi kontra terhadap usulan KH. Abdul Wahid Hasyim, sedangkan diposisi yang mendukung ialah Soepomo dan Soekiman dengan gagasan agar ketentuan yang diusulkan KH. Abdul Wahid Hasyim dipertahankan. Persidangan pun pada akhirnya tidak menemui titik temu dan ditunda

Pada 16 Juli 1945, sidang BPUPKI kembali digelar. Pada saat itu Ir. Soekarno selaku ketua perumus undang-undang mencoba berbicara dihadapan para anggota BPUPKI, pada saat itu Ir. Soekarno mencoba meminta agar semua usulanusulan tidak menjadi perdebatan yang panjang serta menjadikan permusuhan antar golongan karena menurut Ir. Soekarno perjuangan bangsa Indonesia bukan hanya didalam pembahasan tersebut. Maka dari itu ketua persidangan mengambil tindakan untuk menanyakan kepada seluruh anggota BPUPKI agar mengeluarkan pandangannya, tidak lama dari itu kesepakatan didapat dan perumusan hal-hal pokok tersebut disepakati oleh anggota-anggota sidang (Miftahuddin, 2017, hlm. 80-81).

Jelas tergambar peranan $\mathrm{KH}$. Abdul Wahid Hasyim dalam rumusan-rumusan penting bagi kemerdekaan Indonesia, menurut KH. Abdul Wahid Hasyim pada saat itu usulan-usulan tersebutialah bentuk kompromi minimal yang bisa diterima oleh kelompok Islam serta pandangan KH. Abdul Wahid Hasyim atas usulannya ialah bentuk dari perhatian kelompok Islam terhadap kelangsungan Negara Indonesia. 
Pada tanggal 7 Agustus 1945 BPUPKI dibubarkan karena dianggap telah menyelesaikan tugasnya. Sebagai penggantinya segeralah diperoleh ijin dari Jepang untuk membentuk suatu kepanitian yang langsung ditangani oleh orang-orang Indonesia sendiri, kepanitian tersebut diberi nama Panitia Persiapan Kemerdekaan Indonesia (PPKI). Dalam PPKI terhimpun 21 orang yang diantaranya Ir. Soekarno, Drs. Mohammad Hatta, Mr. Soepomo, Dr. Radjiman, K. H. P. Poerbojo, R. P. Soeroso, M. Soetarjo, Soermiharjo, I Goesti Ketoet Poedja, Abdul Kadir, KH. Abdul Wahid Hasyim, Ki Bagoes Hadikusumo, dr. Mohammad Amir, Mr. Abdoel Abbas, Mr. Teuku Mohammad Hasan, A. A. Hamidah, dr. Sam Ratoelangi, Andi Pangeran, Oto Iskandardinata, Mr. Latoehahary, Yap Tjwan Bing.

Pada tanggal 17 Agustus 1945 segeralah dibacakan Proklamasiyang menandai akhir dari penjajahan Indonesia. Pada 17 Agustus 1945 ialah waktu yang sangat terpilih untuk memproklamasikan kemerdekaan Indonesia, karena pada saat itu indonesia dalam momentum sedang tidak dikuasai oleh penjajah. Proklamsi kemerdakan juga sebagai bentuk pernyataan kepada dunia bahwa Indonesia telah Merdeka. Seperti yang tertulis dalam buku Moh. Yamin:

Proklamasi kemerdekaan yang diucapkan dimuka umum tanggal 17 Agustus 1945 itu adalah tingkatan penutup bagi perjuangan kemerdekaan Indonesia dan adalah permulaan zaman pembelaan Negara-Merdeka Republik Indonesia. Serta pernyataan Kemerdekaan Indonesia yang diucapkan di kota Jakarta ialah murni suara rakyat Indonesia kepada dunia bahwa bangsa Indonesia telah cakap dan mampu mengurusi rumah tangganya sendiri. Keterangan kemerdekaan itu mulai ada bahwa revolusi Indonesia sudah bermula. Revolusi ini memusnahkan dan meruntuhkan keadaan yang lama untuk pembentukan negara dan masyarakat baru (Yamin, 1954, hlm. 16).

Maka dari itu Proklamasi yang dibacakan pada 17 Agustus 1945 memiliki makna yang dalam, bahwa Indonesia telah menyatakan kepada dunia luar dan kepada bangsa Indonesia sendiri bahwa sejak saat itu Indonesia telah merdeka. Bagi dunia luar kedudukan indonesia wajib dihormati oleh negara-negara lain secara layak sebagai bangsa dan negara yang mempunyai kedudukan sebagai Negara Merdeka. Sedangkan makna bagi bangsa Indonesia sendiri, untuk memberikan semangat nasionalisme agar tetap mempertahankan tanah airnya.

Periode kemerdekaan Indonesia diakhiri dengan proklamasi yang disuarakan pada tanggal 17 Agustus 1945, sekaligus mengawali Negara Indonesia yang merdeka dan menjadikan Negara Indonesia untuk mengatur Negara sendiri. Kemerdekaan Negara Indonesia juga ialah hasil dari perjuangan dengan mengorbankan segala sesuatu demi kemerdekaannya, serta kemerdekaan yang telah dicapai ialah dasar untuk Negara Indonesia dalam memutuskan dan menentukan masa depan Negara sendiri tanpa campur tangan Negara lain, meskipun pada saat itu keadaan Negara Indonesia belumlah sempurna seutuhnya atas tatanan pemerintahan yang ada.

Pembentukan pemerintahan untuk republik Indonesia yang baru saja diproklamasikan belumlah sampai pada akhir perjuangan. Pada tanggal 18 Agustus 1945, Dalam pelaksanaannya rapat PPKI diselenggarakan tiga kali dengan pembahasan-pembahasan penting 
didalamnya. Dalam rapat pertama, PPKI membahas tentang penetapan Presiden dan Wakil Presiden. Pada pembahasan ini Ir. Soekarno dan Mohammad Hatta terpilih sebagai Presiden dan Wakil Presiden.

Pada rapat PPKI kedua yang dilaksanakan pada tanggal 19 Agustus 1945 membahas tentang pembagian daerah Indonesia. Dalam pembahasan mengenai pembagian wilayah Indonesia disepakati bersama bahwa daerah Indonesia ialah Nederland Indie (bekas jajahan Belanda) dengan jumlah wilayah mencakup delapan wilayah, diantaranya Jawa Barat, Jawa Timur, Jawa Tengah, Sumatra, Kalimantan, Sulawesi, Maluku, dan Sunda Kecil. Setelah pembahasan mengenai pembagian wilayah pada sidang PPKI yang kedua dilanjutkan dengan pembahasan pembentukan Kabinet Republik Indonesia, dibawah lingkungan pemerintah. Dalam pembahasan ini menghasilkan 12 departemen kementerian dan pengangkatan beberapa menteri Negara yang mulai bekerja pada 31 Agustus-14 November 1945, serta beberapa orang Gubernur. Pada saat itu KH. Abdul Wahid Hasyim menjabat sebagai menteri Negara

Pada rapat mengenai revisi tersebut Mohammad Hatta selaku bagian dari badan perubah Undang-Undang Dasar melakukan diplomasi dengan tokoh Islam yang diantaranya, KH. Abdul Wahid Hasyim, Ki Bagus Hadikusumo, Mr. Kasman Singodimedjo, dan Mr. Teku Hasan. Pada diplomasi tersebut Mohammad Hatta memaparkan bahwa ada pihak yang keberatan, terutama orangorang Indonesia Timur. Mohammad Hatta mengaku bahwa informasi keberatan tersebut dianggapnya serius, bahkan jika tidak ada perubahan para orang Indonesia Timur mengancam akan memisahkan diri dari Indonesia. setelah mendengar penjelasan dari Mohammad Hatta, meskipun dengan sedikit perdebatan pada akhirnya ke empat tokoh Islam tersebut menyepakati perubahan tersebut dan sidang kembali dilanjutkan dengan membahas Pembentukan Komite Nasional, Pembentukan Komite Nasional ini bertujuan untuk membantu tugas presiden selama Majelis Permusyawaratan Rakyat belum terbentuk.

Setelah itu dalam sidang PPKI yang ketiga pada tanggal 22 Agustus 1945 membahas tentang pembentukan Komisi Nasional Indonesia Pusat (KNIP). Pada awal pembentukannya KNIP beranggotakan kurang lebih 135 orang. Pemilihan anggota-anggota tersebut dipilih oleh Ir. Soekarno serta dibantu oleh Mohammad Hatta. Pada saat itu anggota-anggota yang dipilih ialah orangorang yang dianggap penting dan bisa diandalkan, banyak orang-orang yang terpilih pada saat itu dan bukan hanya lalaki saja, melainkan perempuan juga banyak yang terlibat terutama orang-orang yang memiliki banyak dukungan dari orang. Dalam tugasnya, KNIP bertugas untuk membantu pekerjaan dan sebagai penasehat Presiden beserta Kabinetnya serta tidak memiliki fungsi legislatif.

Dalam KNIP KH. Abdul Wahid Hasyim termasuk sebagai anggotanya, berita tersebut dimuat dalam surat kabar pada saat itu tentang pengangkatan komposisi komite kerja pemerintah tahun 1945 seperti berikut:

"Komposisi komite kerja. Selain ketua panitia nasional pusat Sjahrir, wakil presiden, Amir Sjarifoedin, dan 
sekretaris Soewandi, anggota berikut juga memiliki anggota sebagai berikut: dr. Soedarsono, dokter di Tjeribon dr. S. Jafroedin, inspektur keuangan tjandoeng, yang mendapatkan gelar dari kapten Belanda, juga seorang ekonom Adam Malik, direktur kantor berita republik antara $\mathrm{Mr}$. Hindromartono, pegawai negeri dari urusan sosial tadjoeloedin, mahasiswa kedokteran dr A. Halim, sekretaris: supine, pegawai negeri sipil di departemen pendidikan Soebadijo, anggota komite nasional pusat S. Mangoen Sarkoro, mantan guru: Wahid Hasyim dan tan ling djie, wakil orang Cina. Tidak ada ekstrimis radikal yang duduk di komite" (Eleeuwarder Koerier, nomor, 6, 02 November 1945).

Pada komposisi komite kerja tahun 1945 ini terlihat ada satu kesenjangan antara kaum agamis dan kaum Nasionalis. Hal tersebut dilihat dari komposisi kepengurusan yang hanya melibatkan sedikit para pemuka Islam. Selanjutnya pada persidangan yang dilaksanakan PPKI juga membahas tentang pembentukan angkatan bersenjata, yang kemudian hari disebut Badan Keamanan Rakyat (BKR). Pada awal pembentukannya, BKR dibentuk berdasarkan unit-unit yang sebelumnya sempat menjadi pasukan Peta atau juga para perwira organisasi pemuda, setelah terkumpulnya mereka maka secara resmi BKR didirikan, pada kesepakatan saat itu BKR bermarkas besar di Jakarta. Usulan demi usulan diterima, hingga pada akhirnya PPKI di bubarkan pada tanggal 29 Agustus 1945.

Setelah kemerdekaan Negara Indonesia yang ditandai dengan
Proklamasi kemerdekaan Indonesia pada 17 Agustus 1945, Negara Indonesia telah syah atas kemerdekaannya dan mampu untuk menjalankan pemerintahannya sendiri tanpa campur tangan Negara lain. Pada awal pembentukan pemerintahan Indonesia diawali dengan Kabinet pertama, yaitu Kabinet Presidensil yang dipimpin langsung oleh Presiden Soekarno. Kabinet Presidensil terbentuk dari musyawarah para anggota PPKI yang dilaksanakan pada rapat terkhirnya.

Pada awal kabinet Presidensil yang dilaksanakan pada 31 Agustus-14 November 1945, tebentuk 12 departemen kementrian dan beberapa menteri Negara. Pada saat itu KH. Abdul Wahid Hasyim terpilih untuk masuk dalam struktur pemerintahan dengan menjabat sebagai Menteri Negara. Pernyataan tersebut diperkuat dengan terbitnya surat kabar yang memberitakan susunan anggota pada Kabinet Presidensil, isi dari surat kabar tersebut seperti berikut:

"Kabinet Indonesia. Anggota "kabinet" Soekamo adalah: urusan dalam negeri: Wiranatakoesoemah; urusan luar negeri: Dr. Soebardjo; keadilan: prof dr Soepomo; pekerjaan sosial: dr ir Soerachman; keuangan: dr Samei; kesehatan masyarakat: Dr Boentaran Martcatmodjo; pendidikan: Ki Hadjar Dewantara; urusan sosial: dr Iwa Cowsoemasoemantri; pertahanan: belum ditunjuk; informasi: Dr Amir Sharifoedin; koneksi: Abikoesno Tjokrosbejoso; ad interim juga menteri negara: Wachid Hashim, Dr Sartono, Dr Maramis dan Otto Iskandar Dinata (Provinciale Drentsche en Asser courant, nomor, 14, 13 November 1945)". 
Pada kabinet Sjahrir tiga KH. Abdul Wahid Hasyim kembali masuk dalam struktur pemerintahan dengan menjabat sebagai Menteri Negara. Pernyataan tersebut diperkuat dengan adanya surat kabar pada susunan kabinet Sjahrir tiga yang menyebutkan KH. Abdul Wahid Hasyim masuk dalam struktur kabinet Sjahrir tiga dari 2 Oktober 1946-27 Juni 1947. Surat kabar tersebut berisi sebagai berikut:

"Kabinet baru-Sjahrir. Komposisi kabinet itu baru dan jabatan Sjahrir ke tiga sekarang dikenal membuat formatur baru. Terdiri dari 3 Sosialis, 5 anggota Masjoemi, 2 dari P.N.I. dan 9 partai loozen atau anggota yang lebih kecilnya. Sultan Djokjakarta adalah Menteri tanpa Portefeuille, Kaum sosialis: Sjahrir, Amir Sjarifoedin dan Soedarsono (tanpa portofolio) mengelola asing bisnis dan pertahanan. Anggota dari P.N.I: Gani dan Soesanto mengelola ecnomics dan keadilan, dari Masjoemi: Sjafroedin, Natsir, Fatoerachman, Wachid Hashim portofolio, menteri-menterinya urusan luar negeri, keuangan, informasi dan ibadah' (Algemeen Handelsblad, nomor, 332, 2 Oktober 1946).

Pada Kabinet Mohammad Hatta yang kedua KH. Abdul Wahid Hasyim barulah masuk pada struktur Kabinet. Pada saat itu KH. Abdul Wahid Hasyim menjabat sebagai Menteri Agama RIS. Kabar tentang susunan Kabinet baru atau Kabinet Mohammad Hatta tersebut diberitakan dalam beberapa surat kabar yang menyebutkan para anggota-anggota dalam Kabinet Mohammad Hatta, kabar tersebut tersiar seperti berikut:
"Pemerintahan pertama RIS telah dilantik pagi hari ini. Daftar resmi berisi beberapa nama berikut: Presiden Menteri: Moh. Hatta, Urusan luar negeri: Moh. Hatta, Urusan dalam negeri: Anak Agung gdeAgung, Dfensie: Sultan Djokja, Tanpa portofolio: Sultan Hamid, Urusan keadilan: Mr. Supomo, Urusan Ekonomi: Ir. Djuanda, Urusan kesehatan: Dr. Leimena, Pengelolaan lalu lintas dan air: Ir. H. Laoh, Urusan Keuangan: Pak Sjarifudin, Urusan sosial: Mr. Kosasih, Urusan Pendidikan: Abuhanifah, Urusan religius: Kiai Wahid Hasyim, Urusan buruh: Wilopo. Kabinet ini memiliki anggota-anggota Loah dan Wilopo dari PNI. Sjafrudin, Moh Roem, kiai Wahid Hasyim dan Abuhanifah dari Masjumi. Leimena, Moh Hatta, Mr. Supomo dan Ir djuanda tanpa partai. Seperti yang diumumkan oleh Presiden Soekarno, kementerian ini adalah Kabinet bisnis Nasional". (Twentsch Dagblad, nomor, 299, 20 Desember 1949).

Dalam kabinet Natsir, KH. Abdul Wahid Hasyim menjabat sebagai Menteri Agama NKRI pertama. Pernyataan tersebut diperkuat dengan adanya berita tentang pengangkatan Natsir sebagai Perdana Menteri sekaligus susunan anggota-anggotanya, surat kabar tersebut berisi seperti berikut:

"KABINET BARU DJAKARTA. Para menteri dari Pemerintah Natsir adalah: Wakil Perdana Menteri keamanan tanah air sultan dari Djokja, non-partai, di luar Urusan Belanda, Moh. Roem (Masjumi): urusan rumah tangga, mantan wakil presiden Djokja Republic Assaat: jusütie, Wongsonegoro, partai besar indonesia: pertahanan, 
Dr. Abdul Halim, parpasang surut: perdagangan dan industri Dr. Sumitro Djojohadikusumo, socia daftar; pertanian, Tandidno Mani, Serikat Petani Indonesia: kesehatan, Dr. J. Leimena, Partai Kristen, Buruh, Dewan Pan Dj I Suroso, Federasi Nasional dasi Urusan sosial, Arudji Kartawinata, sosialis: pendidikan, Dr. Bahder Djohan, tanpa partai; keuangan, Sjafruddin Prawiranegara Masyumi: transportasi, Djuanda tanpa partai: saluran air dan rekonstruksi-struktur, Prof. dr. Joharmes, NatioFederasi nale, urusan Agama Kiai Hadji Wachid Hashim, Masyumi: informasi, M. A. Pellaupessy, Federasi Nasional: tanpa apapun tefeuille, Hasono Tjokroaminota. Ver. Partai Islamis. Kabinet baru akan segera dilantik" (Het nieuws algemeen dagblad, nomor 215 , 7 September 1950).

Dari surat kabar tersebut bisa diambil kesimpulan bahwa KH. Abdul Wahid Hasyim ialah Menteri Agama pertama setelah adanya Negara Kesatuan Republik Indonesia dibawah pimpinan Perdana Menteri Mohammad Natsir.

Pada kabinet Sukiman yang dimulai pada 27 April 1951-3 April 1952. Dalam kabinet ini KH. Abdul Wahid Hasyim menjabat sebagai Menteri Agama kedua kalinya pada masa Negara Kesatuan Republik Indonesia Pernyataan tersebut diperkuat dengan surat kabar yang memberitakan pembentukan Kabinet Sukiman sekaligus para anggotaanggotanya, termasuk KH. Abdul Wahid Hasyim. Berita terpilihnya KH. Abdul Wahid Hasyim sebagai Menteri Agama dimuat dan diberitakan pada surat kabar yang terbit pada tahun 1951. Berita tersebut tersiar seperti berikut:

"Presiden menunjuk menteri yang masuk dan keluar. Pada kesempatan pembebasan kabinet Sukiman, Menteri darikabinetbaru:Dr.Sukiman(Perdana Menteri), Ir. Djuanda (lalu lintas), Mr. Wongsonegoro (pendidikan), Kiai Abdul Wahid Hasyim (Menteri Agama)" (Nieuwsgier, nomor, 196, 28 April 1951).

Dalam kabinet ini KH. Abdul Wahid Hasyim masih dipertahankan menjadi menteri Agama. Kabinet ini juga menjadi kabinet terakhir bagi KH. Abdul Wahid Hasyim untuk menjabat sebelum pada akhirnya KH. Abdul Wahid Hasyim berhenti menjadi menteri Agama. Dalam perjalanannya menjabat sebagai menteri Agama KH. Abdul Wahid Hasyim banyak memberikan perubahan dan gagasan yang terdapat pada kebijakan-kebijakannya.

\section{SIMPULAN}

Berdasarkan hasil penelitian yang telah dilakukan, dapat disimpulkan bahwa KH. Abdul Wahid Hasyim adalah anak dari keluarga terpandang pada saat itu. Ayahnya adalah Kiai Hasjim Asj'ari dan ibunya Nyai Nafiqah. Kiai Hasjim Asj'ari ialah pendiri pondok Pesantren Tebuireng, sekaligus pendiri organisasi kemasyarakatan Nahdlatul Ulama (NU). Sedangkan Nyai Nafiqah ialah putri dari KH. Ilyas, seorang pendiri Pesantren Sewulan Madiun. Dari latar belakang keluarganya, KH. Abdul Wahid Hasyim memiliki garis keturunan keluarga terpandang.

Dalam hal pendidikan KH. Abdul Wahid Hasyim memang berbeda dengan kebanyakan orang pada saat itu. Orang- 
orang pada saat itu kebanyakan sekolah di Holland Inlandsche School (HIS) atau sekolah umum pada jamannya. Perbedaan dalam hal pendidikan tersebut bukan tanpa alasan atau juga bukan karena keluarga KH. Abdul Wahid Hasyim tidak mampu untuk menyekolahkannya ke sekolah umum. Akan tetapi keputusan tersebut ialah satu keputusan yang diambil oleh ayahnya, karena menghawatirkan akan memicu kontroversi dikalangan para ulama yang pada saat itu yang sedang konta dengan Belanda (Penjajah). Maka dari itu ayah KH. Abdul Wahid Hasyim memilih agar tidak memasukan $\mathrm{KH}$. Abdul Wahid Hasyim ke sekolah umum

Karir organisasi KH. Abdul Wahid Hasyim berawal pada tahun 1936, KH. Abdul Wahid Hasyim mendirikan organisasi Ikatan Pelajar-Pelajar Islam (IKPI) yang langsung dipimpin oleh $\mathrm{KH}$. Abdul Wahid Hasyim sendiri. Tujuan awal didirikannya IKPI ialah untuk mewadahi para santri agar bisa berorganisasi, serta bertujuan untuk menampung para santri agar bisa belajar dan mendalami akademik diluar kelas. Organisasi IKPI ini ialah organisasi berbasis akademik yang didalamnya selalu mengadakan kajiankajian terkait dengan akademik, seperti kajian sosial, politik bahkan kajian Agama. IKPI juga mempunyai sekretariat yang menyediakan beberapa fasilitas, seperti ruangan baca dan perpustakaan umum.

Dalam karir organisasi KH. Abdul Wahid Hasyim sangat banyak terlibat dalam banyak organisasi, seperti NU, MIAI, Masyumi, mendirikan Hizbullah, dan banyak lagi. Pada saat sebelum kemerdekaan KH. Abdul Wahid Hasyim terlibat dalam BPUPKI, PPKI, dan dipercaya merumuskan Piagam Jakarta. setelah itu pada saat setelah kemerdekaan KH. Abdul Wahid Hasyim banyak terlibat dalam struktur pemerintahan, diantaranya pada 31 Agustus-14 November 1945 dalam kabinet Presidensil, lalu pada 2 Oktober 1946-27 Juni 1947 dalam kabinet Sjahrir tiga KH. Abdul Wahid Hasyim menjabat sebagai Menteri Negara, setelah itu pada kabinet Mohammad Hatta yang ke dua pada 20 Desember 1949-17 Agustus 1950 KH. Abdul Wahid Hasyim menjabat sebagai Menteri Agama RIS, dilanjut pada kabinet Natsir pada 6 September 195020 Maret 1951 KH. Abdul Wahid Hasyim menjabat sebagai Menteri Agama NKRI yang pertama, dan yang terakhir pada kabinet Sukiman yang dimulai pada 27 April 1951-3 April 1952 dengan menjabat sebagai Menteri Agama NKRI yang keduakalinya.

Selain itu ada juga beberapa kebijakankebijakan KH. Abdul Wahid Hasyim selama menjabat menjadi Menteri ialah merombak susunan Kementerian yang awalnya Kementrian Agama tidak berdiri sendiri menjadi berdiri sendiri, lalu membuat dan memperbaiki badan urusan Haji Indonesia, setelah itu kebijakan KH. Abdul Wahid Hasyim membuat dan mendirikan lembaga-lembaga pendidikan, seperti (PGAN) Pendidikan Guru Agama Negri disetiap karesidenan, mendirikan (SGHAN) Sekolah Guru dan Hakim Agama Negri di Yogyakarta, Bukittinggi, Bandung dan Malang, serta mendirikan (PTAIN) Perguruan Tinggi Agama Islam Negri di Yogyakarta. Kebijakan-kebijakan tersebut tertuang dalam surat-surat keputusan yang disahkan oleh Kementrian agama dan Presiden. Adapun dampak dari kebijakan-kebijakan yang dikeluarkan oleh KH. Abdul Wahid Hasyim lebih mengarah kepada dampak yang positif, terlebih dalam urusan pendidikan yang menjadikan pendidikan agama Islam di Indonesia lebih berkembang. 


\section{DAFTAR PUSTAKA}

\section{Buku}

Aboebakar. (2011). Sejarah Hidup KH. A. Wahid Hasjim. Bandung: PT Mizan Pustaka.

Suryanegara. A. M. (2010). Api Sejarah. Bandung: Salamadani Pustaka Semesta.

Gottschlak, L. (1986). Mengerti Sejarah. Jakarta: Universitas Indonesia Press.

Ismaun. (2005). Pengantar Sejarah sebagai Ilmu dan Wahana Pendidikan. Bandung: Historia Utama Press.

Sjamsuddin, H. (2007). Metodologi Sejarah. Yogyakarta: Ombak.

Redaksi Tempo. (2011). Wahid Hasyim untuk Republik dari Tebuireng. Jakarta: KPG (Kepustakaan Populer Gramedia).

Isno.(2015).PerjuanganLaskar Hizbullah. Jombang: Pustaka Tebuireng.

Kahin, G.M. (2013). Nasionalisme dan Revolusi Indonesia. Depok: Komunitas Bambu.

Lesus. R. (2017). Perjuangan yang Dilupakan: Mengulas perjuangan Umat Islam yang ter(di) lupakan dalam sejarah Indonesia. Yogyakarta: Pro-U Media.
Miftahuddin. (2017). KHA. Wahid Hasyim Peletak Dasar Islam Nusantara. Bandung: Penerbit Marja.

Yamin. M. (1954). Proklamasi dan Konstitusi Republik Indonesia. Jakarta: Penerbit Djambatan.

\section{Surat Kabar}

Berita. (1941, 21 September). Indisch Nieuws NAHDLATOEL OELAMA. Bataviaasch nieuwsblad, hlm. 1

Berita. (1945, 2 November). De samenstelling van het Werk-Comite. Eleeuwarder Koerier, hlm. 2.

Berita. (1945, 13 November). Het Indonesische kabinet. Provinciale Drentsche en Asser courant, hlm. 2.

Berita. (1946, 02 Oktober). Nieuw kabinetSjahrir. Algemeen Handelsblad, hlm. 2.

Berita. (1949, 20 Desember). Het eerste Kabinet van de RIS. Twentsch Dagblad, hlm. 1.

Berita. (1950, 7 September). Kiai Hadji Wahid Hasjim. De Locomotief, hlm. 1.

Berita. (1951, 28 April). Nieuw Kabinet druk besproken. Nieuwsgier, hlm. 1. 